\title{
Synthesis, Reactions and Antimicrobial Activity on Some Novel Phthalazinone Derivatives
}

\section{Fatehia K. Mohamed}

Chemistry Department, Faculty of Science, Fayoum University, Fayoum, Egypt.

\begin{abstract}
A SIMPLE and efficient synthesis of [4-(3, 4-dimethylphenyl)-5, 6, 7, 8-tetrabromo-1-oxo-1H-phthalazin-2-yl]-acetic acid hydrazide (IV) has been carried out. The obtained hydrazide (IV) has been used in synthesis of some interesting heterocycles such as pyrazolone, thiazolidinone, pyrimidine, benzoxazine lactam, rhodanine, quinazoline and benzoxazinone (VIII-XVII). Some of the prepared compounds tested for in vitro antibacterial activities. Among those tested, many compounds showed good antibacterial activities.
\end{abstract}

Keywords: Phthalazinone, Pyrazolone, Thiazolidinone, Azitidinone, Quinazoline, Pyrimidine derivatives and Antimicrobial activity.

The synthesis of new heterocycles containing pthalazine moiety are examples of nitrogen heterocycles that possess exciting biological properties ${ }^{(1-3)}$. Phthalazine has been reported to possess anticonvulsant ${ }^{(4-6)}$, antifungal activity $^{(7)}$ and vasorelaxant activities ${ }^{(8)}$. Additionally, phthalazines have recently been reported to potentially inhibit serotonin reuptake and are considered as anti-depression agents ${ }^{(9,10)}$.

\section{Results and Discussion}

In the present work, the phthalazine derivative (II) has been obtained via the condensation of the aroyl benzoic acid (I) with hydrazine hydrate in boiling ethanol $^{(11,12)}$. The structure of (II) was inferred from elemental analysis and the IR spectrum, which showed stretching bands at 3309, 1706 and $1620 \mathrm{~cm}^{-1}$ corresponding to $\mathrm{NH}, \mathrm{C}=\mathrm{O}$ and $\mathrm{C}=\mathrm{N}$ groups, respectively. The $\mathrm{H}^{1} \mathrm{NMR}$ spectrum revealed the appearance of singlet signal at $\delta 7.2 \mathrm{ppm}$ attributed to the amidic proton $(\underline{\mathrm{NH}}-\mathrm{CO})$, in addition to signals at $\delta 7.45-7.67 \mathrm{ppm}$ attributed to 3 aromatic protons and singlet at $2.34\left(\mathrm{~s}, 6 \mathrm{H}, 2 \mathrm{Ar}-\mathrm{CH}_{3}\right)$. EIMS showed the molecular ion peak at $\mathrm{m} / \mathrm{z} 566$.

Substituted phthalazine was prepared by reacting of (II) with chloroacetyl chloride to give chloroacetyl derivative (III). The IR spectrum of compound (III) showed stretching bands at $1751,1685 \mathrm{~cm}^{-1}$ corresponding to the $\mathrm{C}=\mathrm{O}$ of acid chloride and the $\mathrm{C}=\mathrm{O}$ of cyclic amide. The $\mathrm{H}^{1} \mathrm{NMR}$ spectrum of compound (III) revealed singlet at $\delta 2.34$ attributed to the two methyl protons and the methylenic

e-mail: koranymohammed@yahoo.com 
protons appeared at $\delta 4.75 \mathrm{ppm}\left(-\mathrm{N}-\underline{\mathrm{C}}_{2}-\mathrm{CO}\right)$ also the aromatic protons appeared at $\delta$ 7.45-7.67. Such $\mathrm{H}^{1} \mathrm{NMR}$ data agreed well with the proposed structure.

The structure of the acid chloride derivative (III) was further supported by its reaction with hydrazine hydrate in boiling ethanol, the corresponding hydrazide derivative (IV) was obtained. The IR spectrum of (IV) revealed the disappearance of $\mathrm{C}=\mathrm{O}$ of acid chloride at $1751 \mathrm{~cm}^{-1}$ and the appearance of one broad band at 1705 $\mathrm{cm}^{-1}$ due to the $\mathrm{C}=\mathrm{O}$ of amide and bands at $3263,3312 \mathrm{~cm}^{-1}$ assigned to the $\mathrm{NHNH}_{2}$ group. In addition, the EIMS spectrum of (IV) revealed $\mathrm{m} / \mathrm{z} 553$ which is consistent with $\mathrm{M}^{+}-\mathrm{Br}$ which decomposes to give the different fragments.

The hydrazide (IV) reacted with phenyl isocyanate ${ }^{(13)}$ in boiling benzene to give $\mathrm{N}$ '-phenyl amino carbonyl [4-(3, 4-DimethyI-phenyI)-5, 6, 7, 8-tetrabromo1-oxo-2H-phthalazine-2-yI]-acetic acid hydrazide V. The IR spectrum, showed stretching bands at $3299 \mathrm{~cm}^{-1}$ corresponding to $\mathrm{NH}$ group. $\mathrm{H}^{1} \mathrm{NMR}$ spectrum exhibit multiplet signal at 7.45-7.67 due to 8 aromatic protons, singlet signal at 6.0 corresponding to $\underline{\mathrm{NHNHCO}}$ protons and another singlet due to $\mathrm{CONH} \mathrm{C}_{6} \mathrm{H}_{5}$ proton.

When the hydrazide (IV) and the acetyl acetone were fused together at $160^{\circ} \mathrm{C}$ gave the acetyl acetone monohydrazone (VI). The structure of (VI) was confirmed from IR spectrum, showed stretching bands at 3127,1722,1704 and $1669 \mathrm{~cm}^{-1}$ due to $\mathrm{NH}, \mathrm{C}=\mathrm{O}$ of ketone, $\mathrm{CO}$ of amide and $\mathrm{C}=\mathrm{O}$ of cyclic amide . The ${ }^{1} \mathrm{H}$ NMR spectrum exhibit singlet at 2.34 due to $3 \mathrm{H}$ of $\mathrm{COCH}_{3}, 2.1 \mathrm{ppm}$ due to $\mathrm{N}=\mathrm{C}-\mathrm{CH}_{3}$ and $2.5 \mathrm{ppm}$ due to $2 \mathrm{H}$ of $\mathrm{CH}_{2} \mathrm{COCH}_{3}$.

In a similar manner, fusion of a mixture of acetic acid hydrazide IV and acetic anhydride at $160^{\circ} \mathrm{C}$ afforded acetoxy-N-acetyI-N'-[2-(4-(3,4-dimethyIphenyI) -5,6,7, 8-tetrabromo-1-oxo-2H-phthalazine-2-yl)-acetyl] -hydrazide (VII) in $60 \%$ yield. The formation of (VII) was confirmed by microanalytical and the IR spectrum which revealed the appearance of two bands at $1675,1741 \mathrm{~cm}^{-1}$ due to the $\mathrm{C}=\mathrm{O}$ of amide and acetoxy $\mathrm{C}=\mathrm{O}$ groups, respectively.

Cyclocondensation of the acid hydrazides (IV) with ethyl acetoacetate in absolute ethanol $^{(14)}$ afforded 5,6,7,8-tetrabromo-4-(3,4-dimethylphenyl)-2-[2-(5methyl- 3-oxo-2,3- dihydro-pyrazol-1-yl]- 2-oxo- ethyl) -2H- phthalazin-1-one (VIII). The IR spectrum of (VIII) showed stretching bands at 3327, 1722 and $1665 \mathrm{~cm}^{-1}$ corresponding to $\mathrm{OH}$ and $\mathrm{C}=\mathrm{O}$ groups, respectively. The ${ }^{1} \mathrm{HNMR}$ spectrum of compound (VIII) revealed the appearance of different singlet signals at $\delta 2.30,2.34,4.31$ and 11.40 ppm corresponding to $\underline{\mathrm{CH}}_{3}$. pyrazole, two $\mathrm{Ar}-\underline{\mathrm{CH}}_{3}$, $\mathrm{NCH}_{2} \mathrm{CO}$ - and hydroxyl proton, respectively. The EIMS spectrum revealed an $[\mathrm{M}-2]^{+}$at $\mathrm{m} / \mathrm{z} 702$. 


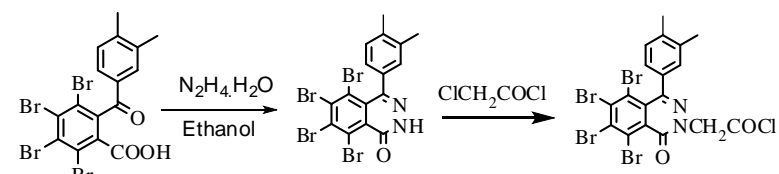

I

II
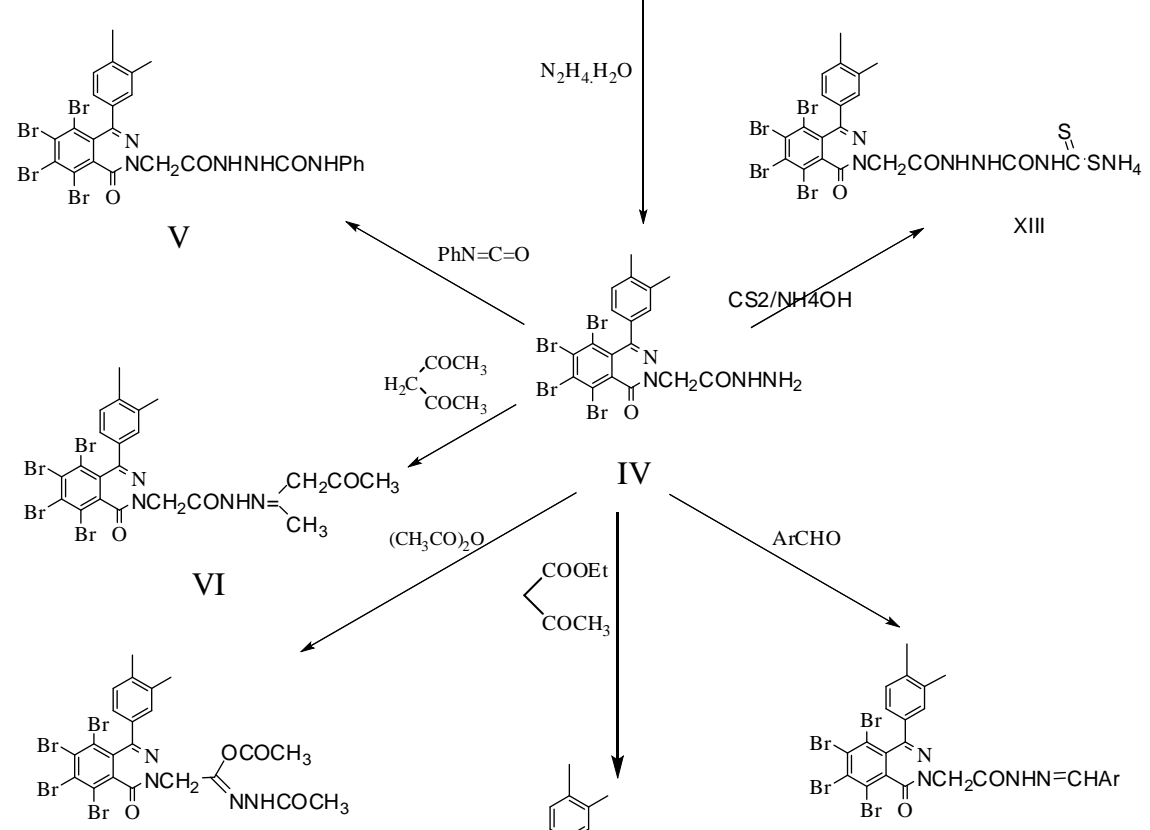

VII

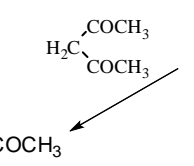

$\mathrm{NCH}_{2} \mathrm{CONHNH}_{2}$

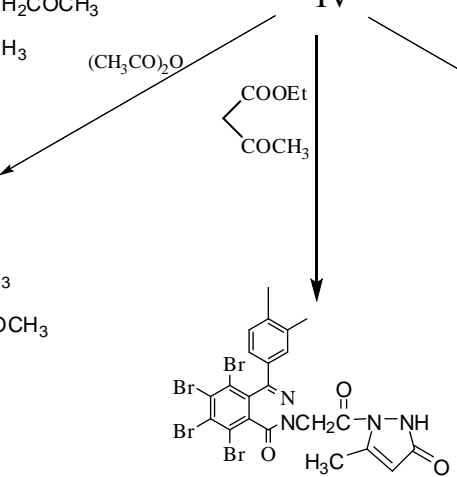

$\mathrm{ArCHO}$

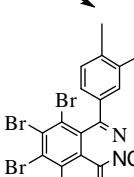

$\overbrace{\mathrm{Br}}^{\mathrm{O}}$

$\mathrm{CH}_{2} \mathrm{CONHN}=\mathrm{CHAr}$

VIII

$$
\begin{aligned}
& \text { IXa-d } \\
& \text { a; } \mathrm{Ar}=-\pi \mathrm{OCH}_{3} \\
& \mathrm{~b} ; \mathrm{Ar}=\text { 《ग } \\
& \mathrm{c} ; \mathrm{Ar}=-\square \mathrm{cl} \\
& \mathrm{d} ; \mathrm{Ar}=\mathbb{1} \mathrm{O}_{\mathrm{O}}
\end{aligned}
$$

Scheme 1

It is interesting to investigate the behavior of the hydrazide (IV) towards aromatic aldehydes ${ }^{(15,16)}$ to obtain corresponding arylidine (IX) which contain $\mathrm{C}=\mathrm{N}$ to investigate its behavior towards aliphatic and aromatic mercaptans under Michael reaction conditions. Thus, treatment of compound (IV) with series of aldehydes such as anisaldehyde , furfural, p-chlorobenzaldehyde and piperonal , afforded [4-(3,4-dimethyl-phenyl)-5,6,7,8-tetrabromo -1-oxo-2H-phthaIazine-2-yI]acetic acid [(1-aryl) methylidene] hydrazide derivatives (IXa-d). The IR spectrum of (IXa) $\left(\mathrm{Ar}=\mathrm{C}_{6} \mathrm{H}_{4}-\mathrm{OCH}_{3}\right)$ showed stretching bands at 3303 and $1704 \mathrm{~cm}^{-1}$ 
corresponding to $\mathrm{NH}$ and $\mathrm{C}=\mathrm{O}$ groups, respectively. The $\mathrm{H}^{1} \mathrm{NMR}$ spectrum of IXc $\left(\mathrm{Ar}=\mathrm{C}_{6} \mathrm{H}_{4}-\mathrm{Cl}\right)$ revealed the appearance of singlet signal at $6.46 \mathrm{ppm}$ due to the olefinic proton of the methine group $\mathrm{N}=\mathrm{CH}-\mathrm{Ar}$. The EIMS spectrum of (IXc) showed the two isotopic molecular ion peak at $\mathrm{m} / \mathrm{z}$ 760,762 together with the fragmentation pattern complying with the structure assigned for the product.

The behavior of activated double bond in the hydrazone (IXa) towards sulphur nucleophiles has been studied ${ }^{(17)}$, in the present investigation when hydrazone (IXa) was allowed to react with thiophenol in the presence of a few drops of piperidine, the product (X) was formed. The IR spectrum of $(\mathrm{X})$ exhibited stretching bands at 3170,1722 and $1673 \mathrm{~cm}^{-1}$ attributed to NH group and two $\mathrm{C}=\mathrm{O}$ groups, respectively.

On the other hand, when the hydrazone (IXa) was allowed to react with thioglycolic acid, addition to $\mathrm{C}=\mathrm{N}$ takes place first, followed by cyclization and the thiazole nucleus attached to the side chain of the phthalazine derivative (XI) was afforded. The IR spectrum of XI showed the presence of $v \mathrm{C}=\mathrm{O}$ of cyclic amide at 1680,1647, v NH at 3184 and $v \mathrm{OH}$ at $3363 \mathrm{~cm}^{-1}$. Such IR data illustrate that phthalazine (XI) is present into three tautomeric forms a, b and c as follows:

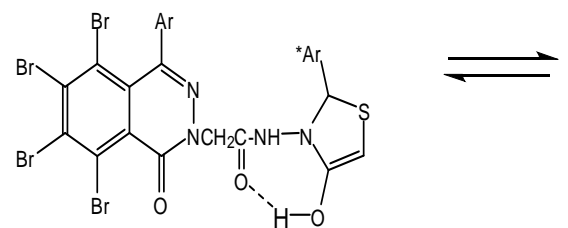

(a)<smiles>O=c1[nH]nc([Al])c2c(Br)c(Br)c(Br)c(Br)c12</smiles>

(b)<smiles>O=C([O-])NN1C(=O)CSC1[Al]</smiles>

(c) 
The tautomers (a) and (b) are stabilized via hydrogen bonding, while the tautomer (c) is more stable than (a) and (b) due to keto form which is more stable than enol form ${ }^{(18,19)}$.

Furthermore, the author and others investigated the behavior of compound (IX) towards cycloaddition reactions ${ }^{(17)}$, thus cholroacetyl chloride cycloadded to the Schiff base (IX) in dry dioxane in the presence of tri ethyl amine as a catalyst to afford $\mathrm{N}$-(3-chloro-2-(4-methoxyphenyl)-4-oxoazetidin-1-yl)-2-(5, 6, 7, 8-tetrabromo-4-(3, 4-dimethylphenyl)-1-oxophthalazin-2(1H)-yl) acetamide (XII). The IR spectrum displayed strong absorption bands at $3183 \mathrm{~cm}^{-1}(\mathrm{NH})$, bands at 1701 and $1687 \mathrm{~cm}^{-1}$ equivalent to $(\mathrm{C}=\mathrm{O})$ groups of cyclic amide and lactam ring, respectively.

Compound (IV) could be converted into dithiocarbamate (XIII) when it stirred with a mixture of carbon disulfide and ammonium hydroxide at room temperature. the IR spectrum showed strong absorption bands at $3423 \mathrm{~cm}^{-1}$ and $1267 \mathrm{~cm}^{-1}$ due to $\mathrm{NH}, \mathrm{C}=\mathrm{S}$ groups, respectively. EIMS spectrum show $\left(\mathrm{M}^{+}\right)$at $\mathrm{m} / \mathrm{z} 729$.

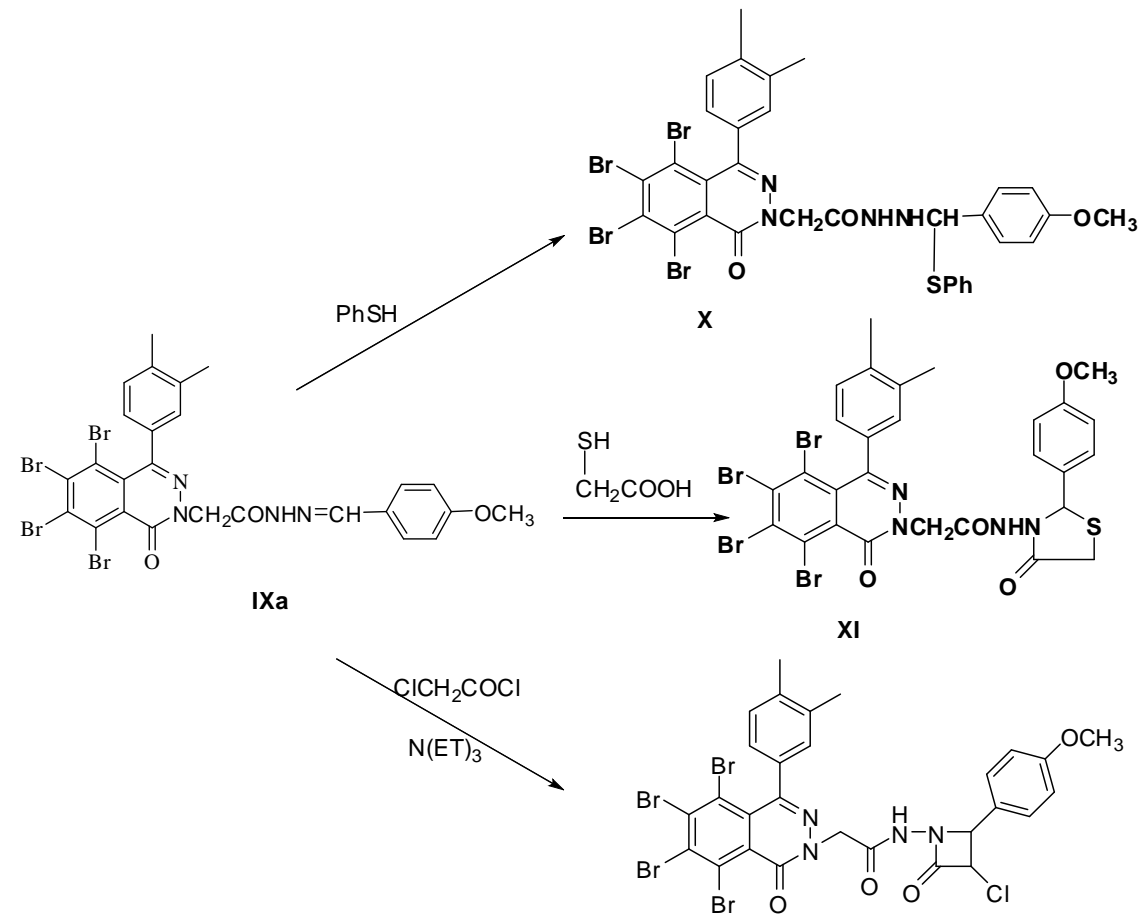

XII

Scheme 2 
Conducting our interest in developing program for studying the behavior of dithiocarbamate compound (XIII) towards alkylating agents such as methyl iodide in order to prepare monomethyl (XIV) and dimethyl derivatives (XV).

Attempts were effort to cyclize the monomethyl compound (XIV) by refluxing with anthranilic acid afforded $\mathrm{N}$-(4-oxo-2-thioxo-1,2-dihydro quinazolin-3(4H)yl)-2- (5,6,7,8- tetrabromo-4- (3,4-dimethylphenyl)-1- oxophthalazin- 2(1H)-yl) acetamide (XVI). When the foregoing reaction was applied using potassium salt of anthranilic acid and dimethyl derivative (XV), N'-(4-oxo-1H-benzo[d][1,3] oxazin2 (4H)-ylidene)-2-(5,6,7,8-tetrabromo-4-(3,4-dimethylphenyl)-1 oxophthalazin -2 (1H)-yl) aceto hydrazide (XVII) was obtained.

The reaction of compound (XIII) with sodium chloroacetate in aqueous medium followed by acidification with concentrated hydrochloric acid afforded $\mathrm{N}$ (4-oxo-2-thioxothiazolidin-3-yl)-2-(5,6,7,8-tetrabromo-4-(3,4-dimethyl-phenyl)- 1oxophthalazin-2(1H)-yl) acetamide (XVIII). The IR spectrum showed strong absorption bands at $3323 \mathrm{~cm}^{-1}$ due to $\mathrm{NH}$ of hydrazine group, at $2857 \& 2925$ $\mathrm{cm}^{-1}$ due to $\mathrm{CH}$ aliphatic, at $1714 \mathrm{~cm}^{-1}$ attributable to $\mathrm{C}=\mathrm{O}$ and at $1255 \mathrm{~cm}^{-1}$ characteristic for $\mathrm{C}=\mathrm{S}$ group .

\section{Antimicrobial activity}

The antimicrobial activity of some of the synthesized compounds was determined in vitro against a variety of bacteria. The tests were carried out using disc diffusion method ${ }^{(20)}$. The compounds were dissolved in DMF, and activity mentioned on 1000ppm. Agar plates were surface inoculated uniformly from fresh broth culture of the gram +ve and gram -ve bacteria.

The discs were incubated at $5^{\circ} \mathrm{C}$ for $1 \mathrm{hr}$ to permit good diffusion then incubated at $28^{\circ} \mathrm{C}$ for $24 \mathrm{hr}$, and the zones of inhibition were measured.

The data obtained in Table 1 indicate that the starting compound (IV) is biologically inactive against gram +ve and gram -ve bacteria. The activity of thiazolidinone (XI) is higher than the activity of the rest of the prepared compounds while Schiff base (IXa) showed no activity against gram +ve bacteria and exhibit only weak activity with Escherichia coli. The $\beta$-lactam derivative (XII) has weak activity against Gram +ve bacteria while showing moderate activity against gram -ve bacteria. 


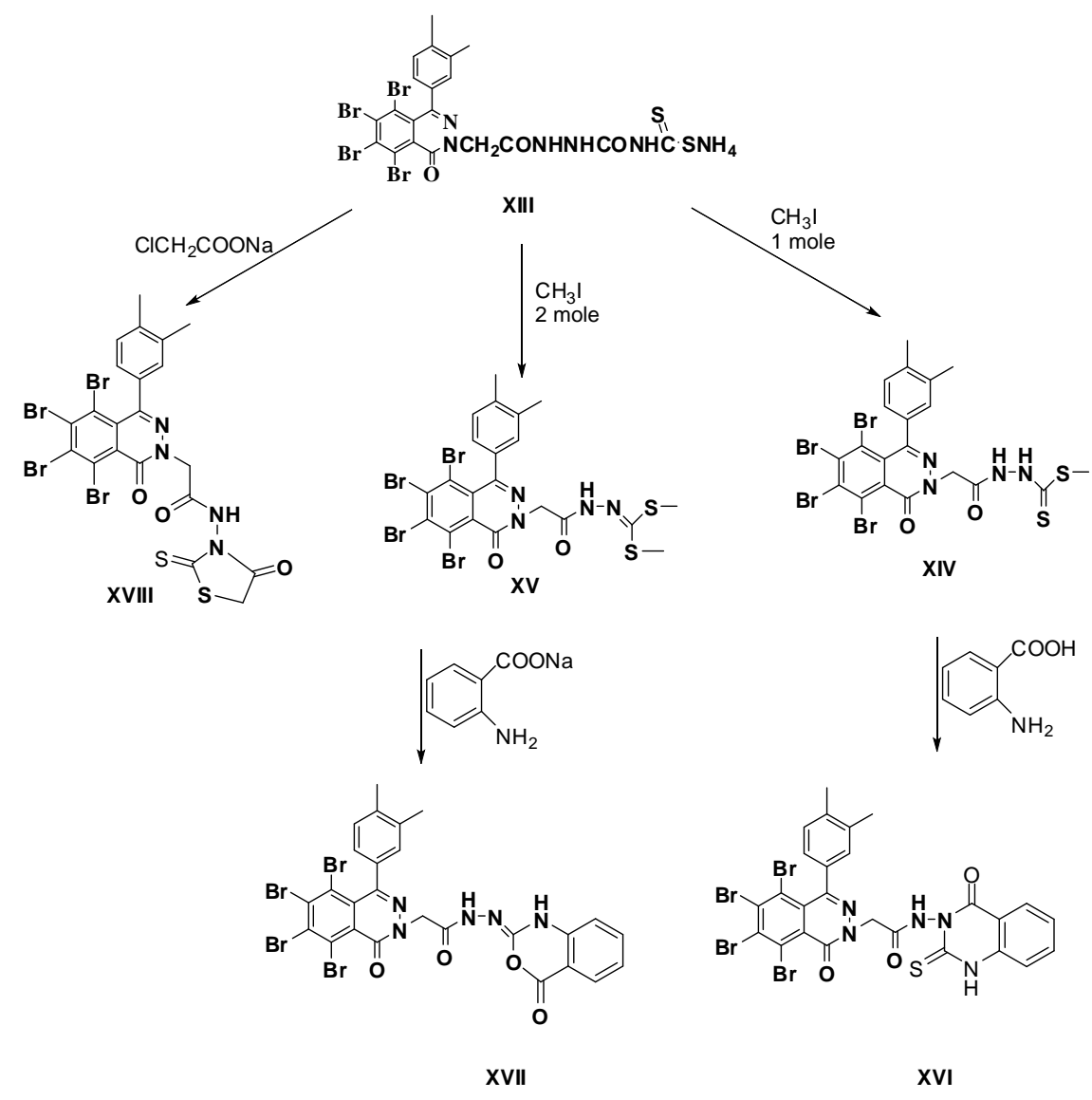

Scheme 3

TABLE 1. Antimicrobial activity of some synthesized compounds IV, IXa, XI and XII.

\begin{tabular}{|c|c|c|c|c|}
\hline \multirow{2}{*}{ Compound } & \multicolumn{4}{|c|}{ Antibacterial activity } \\
\cline { 2 - 5 } & \multicolumn{2}{|c|}{ Gram +ve bacteria } & \multicolumn{2}{c|}{ Gram -ve bacteria } \\
\cline { 2 - 5 } & $\begin{array}{c}\text { Bacillus } \\
\text { subtitles }\end{array}$ & Streptococci & $\begin{array}{c}\text { Klebsiella } \\
\text { pneumonia }\end{array}$ & $\begin{array}{c}\text { Escherichia } \\
\text { coli }\end{array}$ \\
\hline IV & - & - & - & - \\
\hline IXa & - & - & - & + \\
\hline XI & +++ & +++ & ++ & +++ \\
\hline XII & + & + & ++ & ++ \\
\hline Control & - & - & - & - \\
\hline
\end{tabular}


It is quite clear from Table 2 that, the activity of the prepared compounds (XIII, XVI, XVII and XVIII) against gram +ve and gram -ve bacteria, can be arranged as follow:

- Using Streptococci and Escherichia coli all the compounds showed no activity.

- Using Bacillus subtitles, the compounds (XIII) and (XVI) exhibit strong activity, the decrease in potency is noticed as we pass from rodanone ring (XVIII to XVII).

- Using Klebsiella pneumonia, all the compounds are inactive except (XIII and XVI) that showed weak activity.

TABLE 2. Antimicrobial activity of some synthesized compounds XIII, XVI, XVII and XVIII.

\begin{tabular}{|c|c|c|c|c|}
\hline \multirow{2}{*}{ Compound } & \multicolumn{4}{|c|}{ Antibacterial activity } \\
\cline { 2 - 5 } & \multicolumn{2}{|c|}{ Gram +ve bacteria } & \multicolumn{2}{c|}{ Gram -ve bacteria } \\
\cline { 2 - 5 } & $\begin{array}{c}\text { Bacillus } \\
\text { subtitles }\end{array}$ & Streptococci & $\begin{array}{c}\text { Klebsiella } \\
\text { pneumoniea }\end{array}$ & $\begin{array}{c}\text { Escherichia } \\
\text { coli }\end{array}$ \\
\hline XIII & +++ & - & + & - \\
\hline XVI & +++ & - & - & - \\
\hline XVII & - & - & - & - \\
\hline XVIII & ++ & - & + & - \\
\hline Control & - & - & - & - \\
\hline
\end{tabular}

\section{Conclusion}

The screening results revealed that compounds IV, IXa, XI, XII, XIII, XVI, XVII, XVIII have significantly antimicrobial activity, however compound XI is higher biologically active against gram +ve and gram -ve bacteria, while compounds XIII, XVI exhibit strong activity against Basillus subtilis and compounds XII, XVIII showed moderate to considerate to antibacterial activity against the most employed organisms, but the data indicate that compounds IV, IXa, XVII are biologically inactive against gram +ve and gram - ve .

\section{Experimental}

All melting points are uncorrected. Elemental analyses were carried out in the Micro analytical Center, Cairo University. IR spectra (KBr) were recorded on a Bruker FTIR spectrophotometer and ${ }^{1} \mathrm{H}-\mathrm{NMR}$ spectra were recorded in (DMSO $\mathrm{d}_{6}$ and $\mathrm{CDCl}_{3}$ ) on Varian Gemini spectrophotometer at $200 \mathrm{MHz}$ and Varian Mercury spectrophotometer at $300 \mathrm{MHz}$, using tetra methyl silan (TMS) as an internal reference. EIMS were performed at $70 \mathrm{ev}$ with Shimadzu GCMS (QP1000 EX). 
4-(3, 4-Dimethyl-phenyl)-5, 6, 7, 8-tetrabromo-2H-phthalazin-l-one (II)

A mixture of I $(3.4 \mathrm{~g} ; 0.006 \mathrm{~mol})$ and hydrazine hydrate $98 \%(2.7 \mathrm{ml} ; 0.036$ $\mathrm{mol})$ in ethanol $(50 \mathrm{ml})$ was refluxed for $3 \mathrm{hr}$. The reaction mixture was allowed to cool and the separated product was filtered and dried. Crystallization of the crude product from dioxane, afforded (II). Yield $62 \%$, m.p. $272{ }^{\circ} \mathrm{C}$, Anal. Calcd. for $\mathrm{C}_{16} \mathrm{H}_{10} \mathrm{Br}_{4} \mathrm{~N}_{2} \mathrm{O}$, Calculated : C $33.96, \mathrm{H} 1.78, \mathrm{Br} 56.48, \mathrm{~N} 4.95$, Found: C 33.91, H 1.75, Br 56.42, N 4.91. IR(KBr)cm ${ }^{-1}, 3309(\mathrm{NH}), 3061$ (CH, aromatic) , 2916 (CH,aliphatic) and $1706(\mathrm{C}=\mathrm{O}) \cdot{ }^{1} \mathrm{H}-\mathrm{NMR}(200 \mathrm{MHz}$, DMSO-d6 $\delta)$ ppm. $2.34\left(\mathrm{~s}, 6 \mathrm{H}, 2 \mathrm{Ar}-\mathrm{CH}_{3}\right), 7.45(\mathrm{~d}, \mathrm{CH}), 7.57(\mathrm{~s}, \mathrm{CH}), 7.67(\mathrm{~d}, \mathrm{CH})$ and $7.2(\mathrm{~s}, 1 \mathrm{H}, \mathrm{NH})$. Mass:m/z $=\mathrm{M}^{+} 566(81.3 \%), \mathrm{M}^{+}-\mathrm{H}^{\cdot} 565(100 \%), 551$, $537,511,496$.

[4-(3, 4-Dimethyl-phenyl)-5,6, 7, 8-tetrabromo-1-oxo-lH-phthalazin-2-yI]-acetyl chloride (III)

A mixture of phthalazine (II) (1g), chloroacetyl chloride $(5 \mathrm{ml})$ was refluxed for $2 \mathrm{hr}$ on steam bath. The reaction mixture poured into water, and then the mixture was allowed to stand at room temperature overnight. The collected solid was filtered off, washed well with water and dried. Crystallization from Pet.ether (80-100) afforded (III). Yield $98 \%$, m.p. $240^{\circ} \mathrm{C}$, Anal. Calcd. for $\mathrm{C}_{18} \mathrm{H}_{11} \mathrm{Br}_{4} \mathrm{ClN}_{2} \mathrm{O}_{2}$, Calculated : C 33.66, $\mathrm{H} 1.73, \mathrm{Br} 49.76, \mathrm{~N} 4.36, \mathrm{Cl} 5.52$, Found : C 33.61, H 1.70, Br 49.72, N 4.33, Cl 5.49 . IR(KBr) $\mathrm{cm}^{-1}, 1751 \& 1685$ $(2 \mathrm{C}=\mathrm{O}) .{ }^{1} \mathrm{HNMR}\left(200 \mathrm{MHz}, \mathrm{DMSO}-\mathrm{d}_{6} \delta\right) 2.34\left(\mathrm{~s}, 6 \mathrm{H}, 2 \mathrm{ArCH}_{3}\right), 4.75\left(\mathrm{~s}, 2 \mathrm{H}, \mathrm{CH}_{2}\right)$, 7.45(d,CH), 7.57, (s, CH), and 7.67(d, CH).

[4-(3, 4-Dimethyl-phenyl)-5, 6, 7, 8-tetrabromo-l-oxo-lH-phthalazin-2-yI]-acetic acid hydrazide (IV)

A mixture of the acid chloride (III) $(6.4,0.01 \mathrm{~mol}$.) and hydrazine hydrate $(0.015 \mathrm{~mol}, 0.75 \mathrm{ml})$ in ethanol $(50 \mathrm{ml})$ was refluxed for $10 \mathrm{hr}$. The reaction mixture was allowed to cool and the separated product was filtered and dried. Crystallization of the crude product with benzene, afforded (IV). Yield 69\%, m.p. $220^{\circ} \mathrm{C}$, Anal. Calcud. for $\mathrm{C}_{18} \mathrm{H}_{14} \mathrm{Br}_{4} \mathrm{~N}_{4} \mathrm{O}_{2}$. Calculated: C 33.89, H 2.21, Br 50.10, N 8.78, Found : C 33.83, H 2.30, Br 49.81, N 8.72. IR (KBr) $\mathrm{cm}^{-1} 3263$, 3312( $\mathrm{NH}$ and $\left.\mathrm{NH}_{2}\right), 3021(\mathrm{CH}$, aromatic), $2916(\mathrm{CH}$, aliphatic) and $1705(\mathrm{C}=\mathrm{O})$. ${ }^{1} \mathrm{H}-\mathrm{NMR}(200 \mathrm{MHz}, \mathrm{DMSO}-\mathrm{d} 6 \delta) 2.34\left(\mathrm{~s}, 6 \mathrm{H}, 2 \mathrm{ArCH}_{3}\right), 4.09\left(\mathrm{~s}, 2 \mathrm{H}, \mathrm{CH}_{2}\right), 4.22$ $\left(2 \mathrm{H}, \mathrm{NH}_{2}\right), 7.45(\mathrm{~d}, \mathrm{CH}), 7.57(\mathrm{~s}, \mathrm{CH}), 7.67(\mathrm{~d}, \mathrm{CH})$ and $9.08(1 \mathrm{H}, \mathrm{NH})$. Mass $: \mathrm{m} / \mathrm{z}=$ (M-Br) 553(100\%), 133, 105 and 77 (48\%).

$N^{`}$-phenyl amino carbonyl [4-(3, 4-Dimethyl-phenyl)-5, 6, 7, 8-tetrabromo-l-oxolH-phthalazin-2-yI]-acetic acid hydrazide (V)

A mixture of the hydrazide (IV) $(6.39,0.01 \mathrm{~mol})$ and phenylisocyanate $(0.04$ mol, $4.3 \mathrm{ml})$ in dry benzene $(50 \mathrm{ml})$ was refluxed for $10 \mathrm{hr}$ on steam bath. The excess solvent was evaporated and the reaction mixture was crystallized from methanol, afforded (V). Yield $71 \%$, m.p. $170^{\circ} \mathrm{C}$, Anal. Calcud. for $\mathrm{C}_{25} \mathrm{H}_{19} \mathrm{Br}_{4} \mathrm{~N}_{5} \mathrm{O}_{3}$. Calculated : C 39.66, H 2.53, Br 42.22, N 9.25. Found : $\mathrm{C}$ 39.62, H 2.50, Br 42.19, N 9.22. IR (KBr) $\mathrm{cm}^{-1} 3299(\mathrm{NH})$ and 1644 and 1711(2 C=O). ${ }^{1} \mathrm{HNMR}\left(200 \mathrm{MHz}, \mathrm{DMSO}^{-\mathrm{d}_{6}} \delta\right) 2.34$ (s, 6H, two Ar- $\left.\underline{\mathrm{CH}}_{3}\right), 4.09$ 
(s,2H,CH2), $6.0 \quad(\mathrm{~s}, 1 \mathrm{H}, \mathrm{NHNHCO}), 7.45-7.67 \quad(\mathrm{~m}, 8 \mathrm{H}, \quad$ aromaticprotons $), 9.26$ $\left(\mathrm{s}, 1 \mathrm{H}, \mathrm{CONH} \mathrm{C}_{6} \mathrm{H}_{5}\right)$ and $10.08\left(\mathrm{~s}, 1 \mathrm{H}, \mathrm{CH}_{2} \mathrm{CONH}\right)$.

[4-(3, 4-DimethyI-phenyI)-5,6,7,8-tetrabromo-l-oxo-lH-phthalazin-2-yI]-acetic acid [l-methyI-3-oxo-butylidiene]-hydrazide (VI)

A mixture of the acetic acid hydrazide (IV) $(1.9 \mathrm{~g}, 0.003 \mathrm{~mol}$.) and acetyl acetone $(2 \mathrm{ml})$ was heated in an oil bath at $160^{\circ} \mathrm{C}$ for $8 \mathrm{hr}$. The fused mixture was then treated with ethanol and filtered. The crude product was crystallized from toluene. Yield $60 \%$, m.p. $190{ }^{\circ} \mathrm{C}$, Anal. Calcud. for $\mathrm{C}_{23} \mathrm{H}_{20} \mathrm{Br}_{4} \mathrm{~N}_{4} \mathrm{O}_{3}$. Calculated: C 38.37, H 2.80, Br 44.39, N 7.78. Found : C 38.28, H 2.81, Br 44.08, N 7.71. $\mathrm{IR}(\mathrm{KBr}) \mathrm{cm}^{-1} 3127(\mathrm{NH}), 1722,1704$ and $1669(3 \mathrm{C}=\mathrm{O}) .{ }^{1} \mathrm{HNMR}(200 \mathrm{MHz}$, DMSO-d $\left.{ }_{6} \delta\right) 1.49\left(\mathrm{~s}, 3 \mathrm{H}, \mathrm{O}=\mathrm{CCH}_{3}\right), 2.25\left(\mathrm{~s}, 3 \mathrm{H}, \mathrm{N}=\mathrm{C}-\underline{\mathrm{CH}}_{3}\right), 2.34$ (s, 6H, two Ar$\left.\underline{\mathrm{CH}}_{3}\right), 2.5\left(\mathrm{~s}, 2 \mathrm{H}, \underline{\mathrm{CH}}_{2} \mathrm{COCH}_{3}\right), 4.09\left(\mathrm{~s}, 2 \mathrm{H}, \mathrm{N}-\underline{\mathrm{CH}}_{2}-\mathrm{CO}\right), 7.45(\mathrm{~d}, \mathrm{CH}), 7.57(\mathrm{~s}, \mathrm{CH})$, $7.67(\mathrm{~d}, \mathrm{CH})$ and $10.58(\mathrm{~s}, 1 \mathrm{H}, \mathrm{NH})$.

Acetic acid $N^{\prime}$-acetyl-2-(5,6,7,8-tetrabromo-4-(3,4-dimethylphenyl)-1-oxophthalazin2(1H)-yl)acetohydrazonic anhydride (VII)

A mixture of the hydrazide (IV) $(1.9 \mathrm{~g} ; 0.003 \mathrm{~mol})$ and acetic anhydride $(10 \mathrm{ml})$ was refluxed for $7 \mathrm{hr}$. After cooling, the reaction mixture was poured into water; the solid obtained was washed with water several times and crystallized from petroleum ether/ ethanol. Yield $60 \%$, m.p. $200^{\circ} \mathrm{C}$, Anal. Calcd. for $\mathrm{C}_{22} \mathrm{H}_{18} \mathrm{Br}_{4} \mathrm{~N}_{4} \mathrm{O}_{4}$,Calculated : C 36.60, $\mathrm{H}$ 2.51, Br 44.27, $\mathrm{N}$ 7.76, Found : $\mathrm{C}$ 36.58, $\mathrm{H} 2.48, \mathrm{Br} 44.24, \mathrm{~N}$ 7.78. $\mathrm{IR}(\mathrm{KBr}) \mathrm{cm}^{-1} 3288(\mathrm{NH}), 1675$ (amide $\mathrm{C}=\mathrm{O}$ ) and 1741 (acetoxy C=O) . ${ }^{1} \mathrm{HNMR}\left(200 \mathrm{MHz}, \mathrm{DMSO}_{-} \mathrm{d}_{6} \delta\right) \quad 2.04(\mathrm{~s}, 3 \mathrm{H}, \mathrm{NHCO}-$ $\left.\underline{\mathrm{CH}}_{3}\right), 2.12\left(\mathrm{~s}, 3 \mathrm{H}, \mathrm{OCOCH}{ }_{3}\right), 2.34\left(\mathrm{~s}, 6 \mathrm{H}\right.$, two $\left.\mathrm{Ar}-\mathrm{CH}_{3}\right), 3.2\left(\mathrm{~s}, 2 \mathrm{H}, \mathrm{CH}_{2}\right), 7.45$ $(\mathrm{d}, \mathrm{CH}), 7.57(\mathrm{~s}, \mathrm{CH}), 7.67(\mathrm{~d}, \mathrm{CH})$, and $10.58(\mathrm{~s}, 1 \mathrm{H}, \mathrm{NH})$.

5,6,7,8-Tetrabromo-4- (3, 4-dimethylphenyl)-2-(2- (5-hydroxy- 3-methyl-1H-pyrazol1-yl)-2-oxoethyl)phthalazin-1(2H)-one (VIII)

A mixture of the acetic acid hydrazide (IV) $(0.6 \mathrm{~g} ; 0.001 \mathrm{~mol})$, ethyl aceto acetate $(0.126 \mathrm{ml} ; 0.001 \mathrm{~mol})$ was refluxed in ethanol $(20 \mathrm{ml})$ for $12 \mathrm{hr}$. On cooling, the separated solid was filtered off and crystallized from dioxane. Yield $84 \%$, m.p. $288^{\circ} \mathrm{C}$, Anal. Calcd. for $\mathrm{C}_{22} \mathrm{H}_{16} \mathrm{Br}_{4} \mathrm{~N}_{4} \mathrm{O}_{3}$, Calculated : C $37.53, \mathrm{H}$ $2.29, \mathrm{Br} 45.40, \mathrm{~N}$ 7.96, Found : $\mathrm{C}$ 37.48, $\mathrm{H} 2.23, \mathrm{Br} 45.34, \mathrm{~N}$ 7.91. $\mathrm{IR}(\mathrm{KBr}) \mathrm{cm}^{-1} 3227(\mathrm{OH}), 1722$ and $1665(2 \mathrm{C}=\mathrm{O}),{ }^{1} \mathrm{HNMR}\left(200 \mathrm{MHz}, \mathrm{DMSO}-\mathrm{d}_{6}\right.$ d) $2.30\left(\mathrm{~s}, 3 \mathrm{H}, \mathrm{CH}_{3}\right), 2.34\left(\mathrm{~s}, 6 \mathrm{H}\right.$, two $\left.\mathrm{Ar}-\mathrm{CH}_{3}\right), 4.31\left(\mathrm{~s}, 2 \mathrm{H}, \mathrm{CH}_{2}\right), 6.1(\mathrm{~s}, 1 \mathrm{H}$, $\underline{\mathrm{CH}}), 7.45(\mathrm{~d}, \mathrm{CH}), 7.57(\mathrm{~s}, \mathrm{CH}), 7.67(\mathrm{~d}, \mathrm{CH})$, and $11.40(\mathrm{~s}, 1 \mathrm{H}, \mathrm{OH})$.

[4-(3, 4-Dimethyl-phenyl)-5,6,7,8-tetrabromo-l-oxo-2H-phthalazin-2-yI]- acetic acid [(1-aryl) methylidene]- hydrazide (IXa-d)

A mixture of the acetic acid hydrazide (IV) $(6.34 ; 0.01 \mathrm{~mol})$, the appropriate aromatic aldehyde, namely, anisaldehyde, furfural, 4-chloro-benzaldehyde and piperonal ( $0.01 \mathrm{~mol}$.) and few drops of piperidine was refluxed in boiling ethanol $(20 \mathrm{ml})$ for $12 \mathrm{hr}$. After cooling, the collected solid crystallized from the proper solvent. 
IXa : Crystallization from dioxane, Yield $71 \%$, m.p. $170{ }^{\circ} \mathrm{C}$, Anal. Calcd. for $\mathrm{C}_{26} \mathrm{H}_{20} \mathrm{Br}_{4} \mathrm{~N}_{4} \mathrm{O}_{3}$, Calculated : C 41.30, H 2.67, $\mathrm{Br} 42.27, \mathrm{~N} 7.41$, Found : $\mathrm{C}$ 41.23, H 2.66, Br 41.98, N 7.36. IR $(\mathrm{KBr}) \mathrm{cm}^{-1} 3303(\mathrm{NH})$ and $1704(\mathrm{C}=\mathrm{O})$. ${ }^{1} \mathrm{HNMR}\left(200 \mathrm{MHz}, \mathrm{DMSO}-\mathrm{d}_{6} \delta\right) 2.34\left(\mathrm{~s}, 6 \mathrm{H}\right.$, two Ar- $\left.\mathrm{CH}_{3}\right), 3.83\left(\mathrm{~s}, 3 \mathrm{H}, \mathrm{OCH}_{3}\right)$, $4.14\left(\mathrm{~s}, 2 \mathrm{H}, \mathrm{NCH}_{2} \mathrm{CO}\right), 7.06-7.84(\mathrm{~m}, 7 \mathrm{H}$, aromatic protons $), 8.51(\mathrm{~s}, 1 \mathrm{H}, \mathrm{N}=\underline{\mathrm{CH}}-$ Ar) and $10.8(\mathrm{~s}, \mathrm{lH}, \mathrm{NH})$.

IXb : Crystallization from ethanol, Yield $79 \%$, m.p. $280{ }^{\circ} \mathrm{C}$, Anal. Calcd. for $\mathrm{C}_{23} \mathrm{H}_{16} \mathrm{Br}_{4} \mathrm{~N}_{4} \mathrm{O}_{3}$, Calculated : C 38.58, H 2.25, Br 44.64, N 7.82, Found : C 38.41, H 2.22, Br 44.59, N 7.80. IR(KBr) $\mathrm{cm}^{-1} 3133(\mathrm{NH})$ and $1696(\mathrm{C}=\mathrm{O})$. Mass $\mathrm{m} / \mathrm{z}=\mathrm{M}^{+} 704(4.02 \%)$ and $583(100 \%)$.

IXc: Crystallization from ethanol ,Yield 85\%, m.p. $194{ }^{\circ} \mathrm{C}$, Anal. Calcd. for $\mathrm{C}_{25} \mathrm{H}_{17} \mathrm{Br}_{4} \mathrm{ClN}_{4} \mathrm{O}_{2}$,Calculated : $\mathrm{C}$ 39.48, $\mathrm{H}$ 2.25, Br 42.03, N 7.37, $\mathrm{Cl}$ 4.66, Found : C 39.34, H 2.22, Br 41.90, N 7.32, Cl 4.62, IR(KBr)cm $3207(\mathrm{NH})$ and $1659(\mathrm{C}=\mathrm{O}) .{ }^{1} \mathrm{HNMR}\left(200 \mathrm{MHz}, \mathrm{DMSO}^{-\mathrm{d}_{6} \delta}\right) 2.34\left(\mathrm{~s}, 6 \mathrm{H}\right.$, two Ar- $\left.\underline{\mathrm{CH}}_{3}\right)$, $4.14\left(\mathrm{~s}, 2 \mathrm{H}, \mathrm{NCH}_{2} \mathrm{CO}\right), 7.45-7.90(\mathrm{~m}, 7 \mathrm{H}$, aromatic protons), $8.46(\mathrm{~s}, 1 \mathrm{H}, \mathrm{N}=$ $\underline{\mathrm{CH}}-\mathrm{Ar})$ and $10.5(\mathrm{~s}, \mathrm{H}, \mathrm{NH})$. Mass $\mathrm{m} / \mathrm{z}=\mathrm{M}^{+} 760(3.2 \%)$ and $583(100 \%)$.

IXd : Crystallization from ethanol, Yield $82 \%$, m.p. $198^{\circ} \mathrm{C}$, Anal. Calcd. for $\mathrm{C}_{26} \mathrm{H}_{18} \mathrm{Br}_{4} \mathrm{~N}_{4} \mathrm{O}_{4}$, Calculated : C 40.55, H 2.36, Br 41.51, N 7.28, Found : $\mathrm{C}$ $40.40, \mathrm{H} \quad 2.25, \mathrm{Br} \quad 41.35, \mathrm{~N} \quad 7.12$. IR(KBr $) \mathrm{cm}^{-1} 3190(\mathrm{NH})$ and $1650(\mathrm{C}=\mathrm{O})$. ${ }^{1} \mathrm{HNMR}\left(200 \mathrm{MHz}\right.$, DMSO-d 6 d) 2.34 (s, 6H, two $\left.\mathrm{Ar}-\mathrm{CH}_{3}\right), 4.09$ (s, 2H, $\left.\mathrm{NCH}_{2} \mathrm{CO}\right), 7.45-7.77(\mathrm{~m}, 6 \mathrm{H}$, aromatic protons $), 8.54(\mathrm{~s}, 1 \mathrm{H}, \mathrm{N}=\underline{\mathrm{CH}}-\mathrm{Ar})$ and $11.07(\mathrm{~s}, \mathrm{lH}, \mathrm{NH})$.

$N^{\prime}$-(4-Methoxybenzyl)-N'-(phenylthio)-2-(5,6,7,8-tetrabromo-4-(3,4-dimethylphenyl)1-oxophthalazin-2(1H)-yl)acetohydrazide $(X)$

A mixture of the benzylidene derivative (IXa) $(0.75 \mathrm{~g}$; $0.001 \mathrm{~mol})$, thiophenol $(0.165 \mathrm{~g} ; 0.0015 \mathrm{~mol})$ and anhydrous aluminum chloride $(0.5 \mathrm{~g})$ was refluxed in dry DMF $(20 \mathrm{ml})$ and three drops of piperidine for $20 \mathrm{hr}$. The reaction mixture was then poured into water and the precipitated solid was filtered. The residue was washed with water then with hot ethanol. The crude product was crystallized from dioxane. Yield $43 \%$, m.p. $300^{\circ} \mathrm{C}$, Anal. Calcd. For $\mathrm{C}_{32} \mathrm{H}_{26} \mathrm{Br}_{4} \mathrm{~N}_{4} \mathrm{O}_{2} \mathrm{~S}$, Calculated : C 44.73, H 3.03, Br 36.90, N 6.47, S 3.70, Found: C 44.59, $\mathrm{H} 3.18, \mathrm{Br} \quad 37.06, \mathrm{~N} \quad 6.28, \mathrm{~S} 3.73 \mathrm{IR}(\mathrm{KBr}) \mathrm{cm}^{-1} 3170(\mathrm{NH}), 1673$ and 1722(2C=O). ${ }^{1} \mathrm{HNMR}\left(200 \mathrm{MHz}, \mathrm{DMSO}^{-\mathrm{d}_{6}} \delta\right) 2.0$ (s, 1H, NH amine), 2.34 (s, $6 \mathrm{H}$, two Ar- $\left.\underline{\mathrm{CH}}_{3}\right), 3.83$ (s, 3H,O- $\left.\underline{\mathrm{CH}}_{3}\right), 4.09$ (s, $2 \mathrm{H}, \mathrm{NCH}_{2} \mathrm{CO}$ ), 4.95 (s, 1H, NHCH-S $), 6.87-7.67(\mathrm{~m}, 12 \mathrm{H}$, aromatic protons) and $8(\mathrm{~s}, 1 \mathrm{H}, \mathrm{NH} \mathrm{Sec}$. amide).

[4-(3, 4-Dimethyl-phenyl) -5, 6, 7, 8-tetrabromo-1-oxo -lH-phthalazin - 2-yl]$\mathrm{N}$-(4-oxo-2anisyl-thiazolidin-3-yl)-acetamide (XI)

A mixture of (IXa) $(0.75 \mathrm{~g} ; 0.001 \mathrm{~mol})$, thioglycolic acid $(0.165 \mathrm{~g} ; 0.0015 \mathrm{~mol})$, and anhydrous aluminum chloride $(0.5 \mathrm{~g})$ was refluxed in dry DMF (20 ml) and three drops of piperidine for $20 \mathrm{hr}$ under a calcium chloride guard tube. The reaction mixture was then poured into water and the precipitated solid was filtered. 
The residue was washed with water then with hot ethanol. The crude product was crystallized from Pet.-ether (80-100). Yield $65 \%$, m.p. $213{ }^{\circ} \mathrm{C}$, Anal. Calcd. for $\mathrm{C}_{28} \mathrm{H}_{22} \mathrm{Br}_{4} \mathrm{~N}_{4} \mathrm{O}_{4} \mathrm{~S}$, Calculated : $\mathrm{C}$ 40.51, $\mathrm{H}$ 2.67, $\mathrm{Br} 38.50, \mathrm{~N} 6.75, \mathrm{~S} 3.86$, Found : C 40.50, H 2.60, Br 38.55, N 6.81, S 3.81, IR (KBr)cm $\mathrm{cm}^{-1} 3263(\mathrm{NH})$, 3004 (CH aromatic), $2918 \& 2854$ ( $\mathrm{CH}$ aliphatic), and $1680 \quad(\mathrm{C}=\mathrm{O}) .{ }^{1} \mathrm{HNMR}$ $\left(200 \mathrm{MHz}, \mathrm{DMSO}-\mathrm{d}_{6} \delta\right) 2.34\left(\mathrm{~s}, 6 \mathrm{H}\right.$, two $\left.\mathrm{Ar}-\mathrm{CH}_{3}\right), 3.38\left(\mathrm{~s}, 3 \mathrm{H}, \mathrm{O}-\mathrm{CH}_{3}\right), 3.95(\mathrm{~s}$, $\left.2 \mathrm{H}, \mathrm{CO}-\mathrm{CH}_{2}-\mathrm{S}\right), 4.09\left(\mathrm{~s}, 2 \mathrm{H}, \mathrm{NCH}_{2} \mathrm{CO}\right), 5.92(\mathrm{~s}, 1 \mathrm{H}, \mathrm{CH}-\mathrm{S}) .5 .59(\mathrm{~s}, 1 \mathrm{H}, \mathrm{N}-\mathrm{CH}-$ $\mathrm{Ar})$, 7.26-7.67(m, $8 \mathrm{H}$, aromatic protons) and $8(\mathrm{~s}, 1 \mathrm{H}, \mathrm{NH})$.

$N$-(3-chloro-2-(4-methoxyphenyl)-4-oxoazetidin-1-yl)-2-(5, 6, 7, 8-tetrabromo-4(3, 4-dimethylphenyl)-1-oxophthalazin-2(1H)-yl) acetamide (XII)

A mixture of the benzylidene derivative (IXa) $(1.5 \mathrm{~g} ; 0.002 \mathrm{~mol})$, triethyl amine $(0.84 \mathrm{ml} ; 0.006 \mathrm{~mol})$ was dissolved in dry benzene or dry dioxane. Add chloroacetyl chloride $(0.64 \mathrm{ml} ; 0.008 \mathrm{~mol})$ drop wisely to the reaction mixture with stirring through $1 / 2 \mathrm{hr}$. complete stirring for $3 \mathrm{hr}$. The-precipitated solid was filtered, washed with dry benzene or dioxane. Concentrate the filtrate then pour in petridish. Recrystallize the formed solid from Pet.-ether (80-100). Yield $67 \%$, m.p. $142{ }^{\circ} \mathrm{C}$, Anal. Calcd.for $\mathrm{C}_{28} \mathrm{H}_{21} \mathrm{Br}_{4} \mathrm{ClN}_{4} \mathrm{O}_{4}$, Calculated : C 40.39 ,H 2.54, Br 38.39, N 6.73, Cl 4.26 Found : C 40.35 ,H 2.50 ,Br 38.34, N 6.71, Cl 4.21, $\mathrm{IR}(\mathrm{KBr}) \mathrm{cm}^{-1} 3183(\mathrm{NH}), 1701$ and1687 $(2 \mathrm{C}=\mathrm{O}) .{ }^{1} \mathrm{HNMR}\left(200 \mathrm{MHz}, \mathrm{DMSO}^{-\mathrm{d}_{6}}\right.$ б) $2.34\left(\mathrm{~s}, 6 \mathrm{H}\right.$, two $\left.\mathrm{Ar}-\mathrm{CH}_{3}\right), 3.38\left(\mathrm{~s}, 3 \mathrm{H}, \mathrm{O}-\mathrm{CH}_{3}\right), 4.13\left(\mathrm{~s}, 2 \mathrm{H}, \mathrm{NCH}_{2} \mathrm{CO}\right), 5.0(\mathrm{~d}$, $1 \mathrm{H}, \underline{\mathrm{CH}}-\mathrm{Ar}$ propiolactam), $5.45(\mathrm{~d}, 1 \mathrm{H}, \mathrm{CH}-\mathrm{Cl}$ propiolactam), 6.34-7.67 (m,7H, aromatic protons) and $8(\mathrm{~s}, 1 \mathrm{H}, \mathrm{NH})$. Mass: $\mathrm{m} / \mathrm{z}=\mathrm{M}^{+} 832(1 \%)$ and $77(100 \%)$.

Ammonium 2-(2-(5, 6,7,8-tetrabromo-4-(3, 4-dimethylphenyl)-1-oxo phthalazin 2(1H)-yl) acetyl) hydrazinecarbodithioate (XIII)

To a solution of the hydrazide compound (IV) (0.01 mole, $6.34 \mathrm{~g}$ ), in ammonium hydroxide $(40 \mathrm{ml}), 2 \mathrm{ml}$ of carbon disulfide was added dropwise; and left overnight, the solid product formed was filtered off and crystallized from Pet.-ether (80-100) to give (XIII). Yield $52 \%$, m.p. $196^{\circ} \mathrm{C}$, Anal. Calcd. for $\mathrm{C}_{20} \mathrm{H}_{18} \mathrm{Br}_{4} \mathrm{~N}_{6} \mathrm{O}_{3} \mathrm{~S}_{2}$, Calculated : C 31.03, H 2.34, Br 41.29, N $10.86, \mathrm{~S} 8.28$ Found: C 31.10, H 2.31, Br 41.50, N 10.52, S 8.60, IR(KBr)cm $\mathrm{cm}^{-1} 3423(\mathrm{NH})$, $3080(\mathrm{CH}$, aromatic), $2915(\mathrm{CH}$, aliphatic), 1708, $1688(2 \mathrm{C}=\mathrm{O})$ and $1267(\mathrm{C}=\mathrm{S})$. ${ }^{1} \mathrm{HNMR}\left(200 \mathrm{MHz}, \mathrm{DMSO}-\mathrm{d}_{6} \delta\right) 2.3\left(1 \mathrm{H}, \mathrm{NH}\right.$ amine), $2.34\left(\mathrm{~s}, 6 \mathrm{H}, 2 \mathrm{ArCH}_{3}\right), 4.15$ $\left(\mathrm{s}, 2 \mathrm{H}, \mathrm{CH}_{2}\right), 4.22\left(2 \mathrm{H}, \mathrm{NH}_{2}\right), 7.45(\mathrm{~d}, \mathrm{CH}), 7.57(\mathrm{~s}, \mathrm{CH}), 7.67(\mathrm{~d}, \mathrm{CH})$ and 10.08 $\left(1 \mathrm{H}, \mathrm{NH}\right.$ Sec. amide). Mass: $\mathrm{m} / \mathrm{z}=\left(\mathrm{M}^{+}\right) 729(1.6 \%)$ and $\left(\mathrm{M}^{+}-\mathrm{S}\right)(1.4 \%)$.

Methyl 2-(2-(5,6,7,8-tetrabromo-4-(3,4-dimethylphenyl)-1-oxophthalazin-2(1H)yl) acetyl) hydrazine carbodithioate (XIV)

To a solution of dithiocarbamate compound (XIII) $(7.27 \mathrm{~g}, 0.01 \mathrm{~mol})$, in DMF $(30 \mathrm{ml}),(0.93 \mathrm{ml}, 0.015 \mathrm{~mol})$ of methyl iodide was added, the reaction mixture was refluxed for $7 \mathrm{hr}$. Then cooled reaction and poured into ice - cold water, then the separated solid was filtered off, washed well with water and dried. crystallization from dioxane, afforded (XIV). Yield $90 \%$ m.p.298 ${ }^{\circ} \mathrm{C}$, Anal. Calcd. for $\mathrm{C}_{20} \mathrm{H}_{16} \mathrm{Br}_{4} \mathrm{~N}_{4} \mathrm{O}_{2} \mathrm{~S}_{2}$, Calculated : C 32.99, $\mathrm{H} 2.21, \mathrm{Br} 43.90$, N 7.69, S 8.81, Found : C 32.96, H 2.20, Br 43.93, N 7.66, S 8.79, IR(KBr) $\mathrm{cm}^{-1}$

Egypt. J. Chem. 53, No.5 (2010) 
$3291(\mathrm{NH}), 3080(\mathrm{CH}$, aromatic), $2920 \& 2949(\mathrm{CH}$, aliphatic), $1709(\mathrm{C}=\mathrm{O})$ and $1258(\mathrm{C}=\mathrm{S}) .{ }^{1} \mathrm{HNMR}\left(200 \mathrm{MHz}, \mathrm{DMSO}-\mathrm{d}_{6} \delta\right) 2.0(1 \mathrm{H}, \mathrm{NH}$ amine $), 2.34(\mathrm{~s}, 6 \mathrm{H}$, $\left.2 \mathrm{ArCH}_{3}\right), 2.55\left(\mathrm{~s}, 3 \mathrm{H}, \mathrm{S}-\mathrm{CH}_{3}\right), 4.10\left(\mathrm{~s}, 2 \mathrm{H}, \mathrm{CH}_{2}\right), 7.45(\mathrm{~d}, \mathrm{CH}), 7.57(\mathrm{~s}, \mathrm{CH})$, 7.67(d, CH) and 10.0 (1H, NH Sec. amide).

Dimethyl 2-(5,6,7,8-tetrabromo-4-(3, 4-dimethylphenyl)-1-oxophthalazin-2(1H)yl) acetylcarbonohydrazonodithioate $(X V)$

To a solution of dithiocarbamate compound (XIII) $(7.27 \mathrm{~g}, 0.01 \mathrm{~mol}$ ), in DMF $(30 \mathrm{ml}),(1.9 \mathrm{ml}, 0.03 \mathrm{~mol})$ of methyl iodide was added, the reaction mixture was refluxed for $7 \mathrm{hr}$. Then cooled reaction and poured into ice - water, then the separated solid was filtered off, washed well with water and dried. crystallization from dioxane, afforded (XV). Yield $83 \%$, m.p. $347^{\circ} \mathrm{C}$, Anal. Calcd. for $\mathrm{C}_{21} \mathrm{H}_{18} \mathrm{Br}_{4} \mathrm{~N}_{4} \mathrm{O}_{2} \mathrm{~S}_{2}$, Calculated : C 33.99, $\mathrm{H}$ 2.44, $\mathrm{Br}$ 43.07, N 7.55, $\mathrm{S}$ 8.64, Found : C 33.96, H 2.40, Br 43.03, N 7.56. S 8.69, IR(KBr) $\mathrm{cm}^{-1}$ $3214(\mathrm{NH}), 3056(\mathrm{CH}$, aromatic), $2924 \& 2943(\mathrm{CH}$, aliphatic $)$ and $1675(\mathrm{C}=\mathrm{O})$.

$\mathrm{N}$-(4-Oxo-2-thioxo-1, 2-dihydroquinazolin -3 (4H)-yl) -2-(5,6,7,8-tetrabromo-4-(3,4dimethylphenyl)-1-oxophthalazin-2(1H)-yl)acetamide (XVI)

A mixture of monomethyl compound (XIV) $(7.42 \mathrm{~g}, 0.01 \mathrm{~mol})$, in DMF $(30 \mathrm{ml})$ and $(1.37 \mathrm{~g}, 0.01 \mathrm{~mol})$ of anthranilic acid was refluxed for $6 \mathrm{hr}$. Then cool, concentrate, the separated solid was filtered off, washed well with water and dried. Crystallization from the ethanol, afforded (XVI). Yield $47 \%$, m.p. $244^{\circ} \mathrm{C}$, Anal. Calcd. For $\mathrm{C}_{26} \mathrm{H}_{17} \mathrm{Br}_{4} \mathrm{~N}_{5} \mathrm{O}_{3} \mathrm{~S}$,Calculated : C 39.08, H 2.14, $\mathrm{Br} 40.00, \mathrm{~N} 8.76, \mathrm{~S} 4.01$, Found : C 39.02, H 2.10, Br 40.05, N 8.79, S 4.04, IR $(\mathrm{KBr}) \mathrm{cm}^{-1} 3210(\mathrm{NH}), 3023 \& 3072(\mathrm{CH}$, aromatic), $2924(\mathrm{CH}$, aliphatic) and $1663(\mathrm{C}=\mathrm{O}) .{ }^{1} \mathrm{HNMR}\left(200 \mathrm{MHz}, \mathrm{DMSO}_{6} \delta\right) 2.34(\mathrm{~s}, 6 \mathrm{H}$, $\left.2 \mathrm{ArCH}_{3}\right), 4.0\left(1 \mathrm{H}, \mathrm{C}-\mathrm{NH}\right.$ aromatic), $4.9\left(\mathrm{~s}, 2 \mathrm{H}, \mathrm{CH}_{2}\right), 6.99-7.67$ (m, 7H. aromatic protons) and 10.0 (1H, NH Sec. amide).

$N^{\prime}$-(4-oxo-1H-benzo[d][1,3]oxazin-2(4H)-ylidene)-2-(5,6,7,8-tetrabromo-4-(3,4dimethylphenyl)-1-oxophthalazin-2(1H)-yl) acetohydrazide (XVII)

A mixture of dimethyl compound (XV) $(7.56 \mathrm{~g}, 0.01 \mathrm{~mol})$, in DMF $(30 \mathrm{ml})$ and $(1.37 \mathrm{~g}, 0.01 \mathrm{~mol})$ of anthranilic acid. Then 0.01 mole of potassium hydroxide in $2 \mathrm{ml}$ water was added to the reaction mixture. Reflux for $5 \mathrm{hr}$, then cool, concentrate, the separated solid was filtered off, washed well with water and dried. Crystallization from acetic acid afforded (XVII). Yield $56 \%$, m.p. $300{ }^{\circ} \mathrm{C}$, Anal. Calcd. for $\mathrm{C}_{26} \mathrm{H}_{17} \mathrm{Br}_{4} \mathrm{~N}_{5} \mathrm{O}_{4}$, Calculated : C $39.88, \mathrm{H} 2.19, \mathrm{Br} 40.82, \mathrm{~N}$ 8.94 , Found :C 39.84, H 2.15, Br 40.80, N 8.90, $3330 \& 3252(\mathrm{NH}), 3057$ $(\mathrm{CH}$, aromatic), $2929(\mathrm{CH}$, aliphatic) and $1658(\mathrm{C}=\mathrm{O})$.

N-(4-oxo-2-thioxothiazolidin-3-yl)-2-(5,6,7,8-tetrabromo-4-(3,4-dimethyl phenyl)1-oxophthalazin-2(1H)-yl) acetamide (XVIII)

To an aqueous solution of sodium chloroacetate $(0.01 \mathrm{~mol}, 7.27 \mathrm{~g}, 0.01 \mathrm{~mol})$ dithiocarbamate compound (XIII) was added portion wise during 10 min with stirring. The stirring was continued at room temperature for $3 \mathrm{hr}$. Then a hot solution of concentrated hydrochloric acid $(66 \mathrm{ml})$ and water $(26 \mathrm{ml})$ was added. 
On cooling a precipitate was formed which was filtered off and crystallized from ethanol, afforded (XVIII). Yield $42 \%$, m.p. $199^{\circ} \mathrm{C}$, Anal. Calcd. for $\mathrm{C}_{21} \mathrm{H}_{14} \mathrm{Br}_{4} \mathrm{~N}_{4} \mathrm{O}_{3} \mathrm{~S}_{2}$, Calculated : C 33.45, H 1.87, $\mathrm{Br} 42.38, \mathrm{~N}$ 7.43, S 8.50, Found: C 33.22, H 1.74, Br 42.02, N 7.30, S 8.77. IR $(\mathrm{KBr}) \mathrm{cm}^{-1} 3323(\mathrm{NH})$, $3080(\mathrm{CH}$, aromatic), $2857 \& 2925(\mathrm{CH}$, aliphatic), $1714(\mathrm{C}=\mathrm{O})$ and 1255 $(\mathrm{C}=\mathrm{S}) .{ }^{1} \mathrm{HNMR}\left(200 \mathrm{MHz}, \mathrm{DMSO}-\mathrm{d}_{6} \delta\right) 2.34\left(\mathrm{~s}, 6 \mathrm{H}, 2 \mathrm{ArCH}_{3}\right), 4.11(\mathrm{~s}, 2 \mathrm{H}$, $\left.\mathrm{SCH}_{2}\right), 4.3\left(\mathrm{~s}, 2 \mathrm{H}, \mathrm{CH}_{2}\right), 7.45-7.67(\mathrm{~m}, 3 \mathrm{H}$. aromatic protons) and $10.9(1 \mathrm{H}, \mathrm{NH}$ Sec. amide).

\section{References}

1. Salvi, K.V. , Bhambi, D., Jat, L.J. and Talesara, L.G., Synthesis and antimicrobial activity of some 2-[1-(4-oxo- 3,4- dihydrophthalazine-1-yl) alkyl]- $1 \mathrm{H}$-isoindole-1,3 $(2 \mathrm{H})$ - dione and their imidoxy derivatives. ARKIVOC, 14, 133 (2006).

2. Carling, R.W., Moore, K.W., Street, L.J., Wild, D., Isted, C., leeson, P.D., Thomas, S., Connor, D., Mckernan, R.M., Quirk, K., Cook, S.M., Atack, J.R., Wafford, K.A., Thompson, S.A., Dawson, G.R., Ferris, P., Castro, J.L., 3-Phenyl-6-(2pyridyl) methyloxy-1,2,4-triazolo[3,4-a]phthalazines and analogues: high-affinity gamma-aminobutyric acid-A benzodiazepine receptor ligands with alpha 2, alpha 3, and alpha 5-subtype binding selectivity over alpha 1. J. Med. Chem. 47, 1807 (2004).

3. Seref Demirayak, S., Karaburun, C.A. and Beis, R., Some pyrrole substituted aryl pyridazinone and phthalazinone derivatives and their antihypertensive activities. Eur. J. Med. Chem. 39 , 1089 (2004).

4. Strappaghetti, G., Brodi, C., Giannaccini, G. and Betti, L., New 4-(4-methylphenyl) phthalazin-1(2H)-one derivatives and their effects on alpha1-receptors. Bioorg. Med. Chem. Lett., 16, 2575 (2006).

5. Haack, T., Fattori, R., Napoletano, M., Pellacini, F., Fronza, G., Raffaini, G., Ganazzoli, F., Phthalazine PDE IV inhibitors: conformational study of some 6methoxy-1,4-disubstitutedderivatives. Bioorg. Med. Chem., 13, 4425 (2005).

6. EI Nezhawy, H.O.A., Radwan, A.A.M., Samir, T. and Gaballah, T.S., Synthesis of chiral N-(2-(1-oxophthalazin-2(1H)-yl) ethanoyl)- $\alpha$-amino acid derivatives as antitumor agents. ARKIVOC, 12, 119 (2009) .

7. Ryu, C.K., Park, R.E., Yaung, M.M. and Nho, Z.H., Synthesis and antifungal activity of 6-arylamino-phthalazine-5,8-diones and 6,7-bis(arylthio)-phthalazine-5,8diones,J.Bioorg. Lett.,17, 2577 (2007) .

8. Delolmo, E., Barboza, B., Ybarra, M.I., Lopez-Perez, J.L., Carron, R., R., Sevilla, M.A., Boselli, C., Feliciano, A.S., Vasorelaxant activity of phthalazinones and related compounds. Bioorg. Chem. Lett. 16, 2786 (2006).

9. Menear, K.A., Adcock, C., Alonso, F.C., Blackburn , K., Copsey, L., Drzewiecki, J., Fundo , A., LeGall, A., Gomez, S., Javaid, H., Lenc, C.F., Martin, N.M.B., Mydlowski, C., Smith, G.C.M., Bioorg. Med. Chem. Lett. 18, 3942 (2008). 
10. Cashman, J.R., VolKer, T., Johnson, R. and Janowsky, A., Stereoselective inhibition of serotonin re-uptake and phosphodiesterase by dual inhibitors as potential agents for depression. Bioorg. Med. Chem. 17, 337 (2009).

11. Sivakumar, R., Gnanasam, K.S. and Ramachandran, S., Pharmacological evaluation of some new 1-substituted-4-hydroxy-phthalazines. Eur. J. Med. Chem. 37 793 (2002).

12. Mohammed, F.K., Bakeer, H.M. and EL-Hashash, M.A., Studies on 2-substituted6,8-dibromo-4(H) - 3,1-benzoxazine-4-one. Asian J. Chem. 21 (7), 5004 (2009).

13. El-Hashash, A.M., Egypt. J. Chem. 45, 881 (2002).

14. Khan, R., Uddin, I.M., Alam, S.M., Hossain, M.M. and Islam, R.M., Synthesis and preliminary evaluation of brominated 5-methyl-2,4-dihydropyrazol-3-one and its derivatives as cytotoxic agents. Bangladesh J. Pharmacol. 3, 27 (2008).

15. El-Masry, H.A., Fahmy, H.H. and Abdelwahed, S.H., High-level computational study of the site-, facial- and stereoselectivities for the diels-alder reaction between obenzoquinone and norbornadiene. Molecules, 5, 1417 (2000).

16. Vasoya, S.L., Patel, R.M., Dobaria,V.S. and Joshi, S.H., Facile synthesis of some new azetidinones and acetyl oxadiazoles bearing benzo[b]thiophene nucleus as a potent biological active agent. Indian J. Chem. 44B, 405 (2005).

17. Mohammed, F.K., Essway, A.I. and Badry, M.G., Facile and convenient synthesis of novel benzopyranopyrimidine derivatives. Asian J. Chem. 21 (8), 5873 (2009).

18. Ingold, C.K., Structure and Mechanism in Organic Chemistry, $2^{\text {nd }}$ ed., C. Bell and Sons, Ltd, p.134 (1969).

19. El-Hashash, M.A., El-Nagdy, S.I. and Solimann, A.Y., Synthesis and reactions of 4-(3',4'-dichloro)phenyl- 1(2H)- phtalizinone. Egypt. J. Chem. 29 (5) , 529 (1986).

20. Collee, G.J., Fraser, G.A., Marmion, P.B. and Simmons, A., Practical Medical Microbiology, 14 ${ }^{\text {th }}$ Ed., Churchill Livingstone: Edinburgh, 11, 163 (1996).

( Received 26/4/2010;

accepted 26/10/2010) 


\section{تشــييا وتفـاعلات بعض مشـتقات الفيثـالازينون الجديــة ودراســة \\ نشاطها البيولوجى}

$$
\text { قتحمية قرنى محمد }
$$

في هذا البحث تم تحضير مركب الفيثالازين (II) من تكاتف حمض الارويل

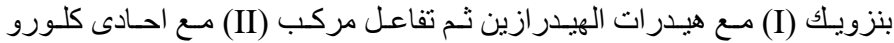

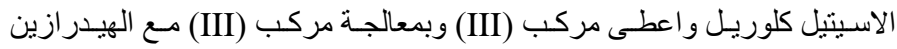

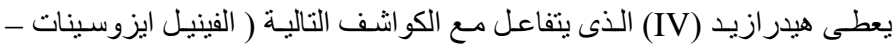

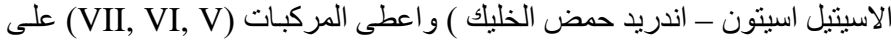

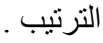

وبالتكاثف الحلقى لمركب (IV) مع استر اسيتو اسيتات الايثيل اعطى مركب

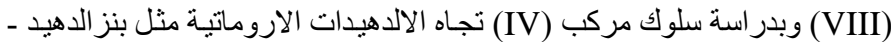

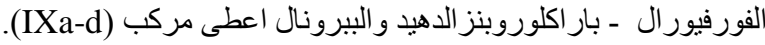

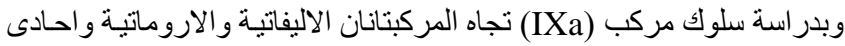

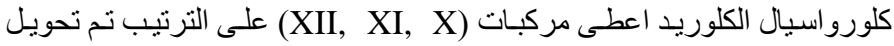

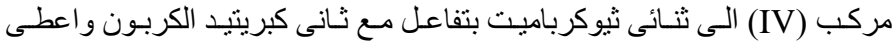

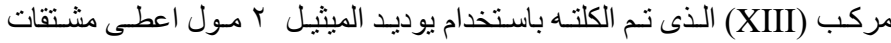

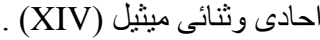

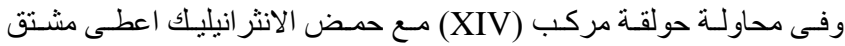

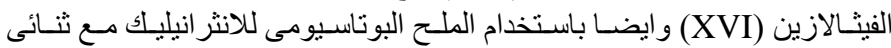

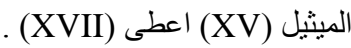

وبتفاعل مركب (XIII) مـع احسادى كلورواسيتات الصوديوم اعطى مركب

وتم اثبـات المركبـات المحضرة بالتحليل العنصـرى وكذلك الدر اسـات الطيفية المختلفة وتم (IR , H-NMR , Mass spectroscopy)

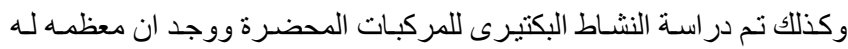

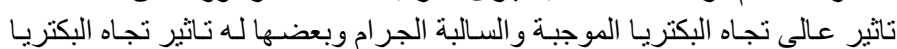
موجبة الجر ام فقط. 